\title{
Risk factors for anastomotic leakage after laparoscopic low anterior resection with DST anastomosis
}

\author{
Kenji Kawada $\cdot$ Suguru Hasegawa $\cdot$ Koya Hida $\cdot$ Kenjiro Hirai $\cdot$ \\ Kae Okoshi $\cdot$ Akinari Nomura $\cdot$ Junichiro Kawamura • \\ Satoshi Nagayama $\cdot$ Yoshiharu Sakai
}

Received: 21 March 2014/Accepted: 13 April 2014/Published online: 23 May 2014

(C) The Author(s) 2014. This article is published with open access at Springerlink.com

\begin{abstract}
Background Laparoscopic rectal surgery involving rectal transection and anastomosis with stapling devices is technically difficult. The aim of this study was to evaluate the risk factors for anastomotic leakage (AL) after laparoscopic low anterior resection (LAR) with double-stapling technique (DST) anastomosis.

Methods This was a retrospective single-institution study of 154 rectal cancer patients who underwent laparoscopic LAR with DST anastomosis between June 2005 and August 2013. Patient-, tumor-, and surgery-related variables were examined by univariate and multivariate analyses. The outcome of interest was clinical AL.
\end{abstract}

K. Kawada $(\bowtie) \cdot S$. Hasegawa $\cdot$ K. Hida $\cdot$ K. Hirai · Y. Sakai Department of Surgery, Graduate School of Medicine, Kyoto

University, 54 Shogoin-Kawara-cho, Sakyo-ku,

Kyoto 606-8507, Japan

e-mail: kkawada@kuhp.kyoto-u.ac.jp

S. Hasegawa

e-mail: shase@kuhp.kyoto-u.ac.jp

K. Okoshi

Department of Surgery, Japan Baptist Hospital, Kyoto, Japan

\author{
A. Nomura \\ Department of Surgery, Graduate School of Medicine, Saga \\ University, Saga, Japan
}

J. Kawamura

Department of Surgery, Shiga Medical Center for Adults,

Moriyama, Japan

\section{S. Nagayama}

Department of Gastroenterological Surgery, Gastroenterological Center, Cancer Institute Hospital, Japanese Foundation for

Cancer Research, Tokyo, Japan
Results The overall AL rate was $12.3 \%$ (19/154). In univariate analysis, tumor size $(P=0.001)$, operative time $(P=0.049)$, intraoperative bleeding $(P=0.037)$, lateral lymph node dissection $(P=0.009)$, multiple firings of the linear stapler $(P=0.041)$, and precompression before stapler firings $(P=0.008)$ were significantly associated with AL. Multivariate analysis identified tumor size (odds ratio [OR] 4.01; $95 \%$ confidence interval [CI] 1.25-12.89; $P=0.02)$ and precompression before stapler firings (OR 4.58; CI 1.22-17.20; $P=0.024$ ) as independent risk factors for AL. In particular, precompression before stapler firing tended to reduce the AL occurring in early postoperative period.

Conclusions Using appropriate techniques, laparoscopic LAR with DST anastomosis can be performed safely without increasing the risk of AL. Important risk factors for AL were tumor size and precompression before stapler firings.

Keywords Rectal cancer - Anastomotic leakage . Double-stapling technique $\cdot$ Laparoscopic low anterior resection

Total mesorectal excision (TME) was introduced by Heald in 1982 [1] and has been accepted as the standard technique for rectal surgery because it decreases local recurrence and improves functional results. Laparoscopic surgery for colon cancer was introduced in the 1990s, and has shown promising results. Laparoscopic low anterior resection (LAR) for rectal cancer is technically more difficult than laparoscopic colectomy for colon cancer because of the difficulties related to rectal transection and anastomosis within a narrow pelvic space. A higher incidence of positive circumferential margins after laparoscopic LAR was 
shown in an initial controlled trial [2], but an increasing number of recent studies have shown that laparoscopic surgery for rectal cancer is safe and feasible [3-7].

Anastomotic leakage (AL) is the most common complication after rectal cancer surgery and can result in not only increased morbidity and mortality but also increased local recurrence and poorer prognosis [8-10]. The doublestapling technique (DST) has greatly facilitated intestinal reconstruction especially for anastomosis after LAR. Despite technical improvements and instrumental developments, recent studies have reported that the $\mathrm{AL}$ rate remains at $6.3-13.7 \%$; the most commonly reported rate is approximately $10 \%[7,9,11-14]$. Risk factor analyses for AL after open LAR have been widely reported. However, a few studies have analyzed the risk factors for AL after laparoscopic LAR [14-18]. In addition, the rates of protective diverting stoma, preoperative chemoradiotherapy, and TME in each study were not consistent, which might produce different results. In the present study, cases with protective diverting stoma or preoperative chemoradiotherapy were excluded from the analysis to investigate the pure risk factor for AL.

We previously reported that precompression before stapler firings is a critical factor for gaining successful staple formation in an animal model [19]. To our knowledge, this is the first study to investigate the effect of precompression before stapler firings in a clinical setting. The aim of the present study was to identify the risk factors associated with AL in a single institution where standardized laparoscopic LAR with DST anastomosis was performed.

\section{Materials and methods}

\section{Study population}

A total of consecutive 162 patients underwent elective laparoscopic LAR with DST anastomosis at Kyoto University Hospital between June 2005 and August 2013. Among those patients, eight patients were excluded because they had the following factors: a tumor histopathology other than adenocarcinoma $(n=1)$; construction of protective diverting stoma $(n=4)$; conversion to open surgery $(n=3)$. Finally, a total of 154 patients with primary rectal cancers were included in this retrospective study. No patients had preoperative radiotherapy or chemoradiotherapy. The lower edge of the tumor was within $10 \mathrm{~cm}$ from the anal verge in all cases. Tumors located between the inferior margin of the second sacral vertebra and the peritoneal reflection were recorded as the upper rectum, while those located below the peritoneal reflection were recorded as the lower rectum [20]. The location of the tumor was determined by pelvic computed tomography, colonoscopy, and/or barium enema preoperatively and confirmed during surgery. The following patient-, tumor-, and surgery-related 25 variables were included in the analysis: patient-related [age, sex, body mass index (BMI), preoperative serum albumin and hemoglobin levels, preoperative chemotherapy], tumor-related (tumor location, maximum tumor diameter, UICC-TNM stage (7th edition) [21], lymphatic invasion, venous invasion), and surgeryrelated (operative time, intraoperative bleeding, level of inferior mesenteric artery (IMA) ligation, lateral lymph node dissection, simultaneous resection of other organs, number of cartridges of the linear stapler used for rectal transection, size of the circular stapler, height of the anastomosis from the anal verge, removal of crossing point where two staple lines intersected, precompression before stapler firings, placement of a pelvic drain, placement of a transanal tube). Written informed consent was obtained from all patients for the use of their clinical data in the future.

\section{Surgical method}

All procedures were conducted by well-experienced, boardcertified laparoscopic colorectal surgeons at our institution. All patients received standard bowel preparation and antibiotic prophylaxis. The surgical technique was standardized, as described previously [22, 23]. High ligation of IMA was routinely performed, although low ligation of IMA (preservation of left colic artery) was performed depending on the condition of the patient's blood vessel. The splenic flexure was mobilized totally or partially, depending on the bowel length. After mobilization of the left colon, tumorspecific mesorectal excision, including TME (according to the tumor location), was performed as the standard surgical technique. The main principle of this technique is sharp mesorectal dissection with a nerve-preserving technique. After clamping distal to the tumor to allow washout of the rectal stump, the rectum was transected using the linear stapler (Echelon 60 or Endo-Cutter, Ethicon Endo-Surgery, Cincinnati, OH, USA). After the surgical specimens were removed through the small incision, the anvil of the circular stapler was positioned in the proximal colon. The circular stapler (CDH, Ethicon) was inserted though the rectum, and then end-to-end DST anastomosis was completed intracorporeally. The "doughnut" created after anastomosis was inspected for completeness. Air-tightness was routinely tested by the transanal instillation of air. The height of anastomosis from the anal verge was measured by the digital rectal examination during anesthesia. Cases with protective diverting stoma were excluded. Cases converted to a transanal hand-sewn coloanal anastomosis were also excluded. 
Definition of clinical anastomotic leakage

Clinical leakage signs were defined as abdominal pain, fever, pus, or fecal discharge from the pelvic drain, peritonitis, and pelvic abscess. All clinically suspicious symptoms were confirmed by digital rectal examination, sigmoidoscopy and radiographic examination (e.g., extravasation of endoluminally administered water-soluble contrast enema, abscess at the level of anastomosis, and fluid/air bubbles surrounding the anastomosis on computed tomography). The diagnosis of AL was done within 30 days after surgery. Using the proposed grading system [24], AL was classified into three grades: grade A required no active therapeutic intervention; grade $B$ required active therapeutic intervention; and grade $\mathrm{C}$ required re-operation. We included symptomatic AL (grade B and C) for primary endpoint analysis. Asymptomatic AL (grade A) was not considered, because routine contrast enemas were not performed after surgery in our institution.

\section{Statistical analysis}

All statistical analyses were performed using the SPSS software, version 11.50 (SPSS Inc, Chicago, IL, USA). The Chi-square test, Fisher's exact test, and Mann-Whitney $U$ test were used for categorical variables comparison and analysis. All analyses were two-sided, and a $P$ value of $<0.05$ was considered statistically significant. To determine factors associated with $\mathrm{AL}$, multivariate logistic regression analysis was used and factors with a $P$ value of $<0.05$ were included in the model.

\section{Results}

Patients population

In total, consecutive 162 patients underwent elective laparoscopic LAR with end-to-end DST anastomosis. To investigate the pure risk factors of $\mathrm{AL}$, patients with the following factors were excluded: a tumor histopathology other than adenocarcinoma $(n=1)$, construction of protective diverting ileostomy $(n=4)$, and conversion to open surgery $(n=3)$. Therefore, a total of 154 patients were enrolled for analysis. Patient characteristics are listed in Table 1. Among 154 patients, $111(72.1 \%)$ were male and $43(27.9 \%)$ were female. The median age was 66 years old (range 36-88). Their median BMI was 21.6 (range 10.5-30.0). The lower edge of the tumor was within $10 \mathrm{~cm}$ from the anal verge in all cases. A total of 101 patients $(65.6 \%)$ had the upper rectal cancer, and the remaining 53 patients $(34.4 \%)$ had the lower rectal cancer. Preoperative chemotherapy was performed in 25 patients (16.2\%).
Table 1 Patient and tumor characteristics $(n=154)$

\begin{tabular}{|c|c|c|}
\hline Characteristics & & $\begin{array}{l}\text { No. of } \\
\text { Patients }\end{array}$ \\
\hline \multicolumn{3}{|l|}{ Age (years) } \\
\hline Median \pm SD (range) & $66 \pm 9.9(36-88)$ & \\
\hline \multicolumn{3}{|l|}{ BMI $\left(\mathrm{kg} / \mathrm{m}^{2}\right)$} \\
\hline Median \pm SD (range) & $21.6 \pm 3.2(10.5-30.0)$ & \\
\hline \multicolumn{3}{|l|}{ Sex } \\
\hline Male & & 111 \\
\hline Female & & 43 \\
\hline \multicolumn{3}{|l|}{ Location } \\
\hline Upper & & 101 \\
\hline Lower & & 53 \\
\hline \multicolumn{3}{|l|}{ UICC-TNM Stage } \\
\hline 0 & & 2 \\
\hline I & & 45 \\
\hline II & & 61 \\
\hline III & & 34 \\
\hline IV & & 12 \\
\hline \multicolumn{3}{|l|}{$\mathrm{T}$ category } \\
\hline Tis & & 2 \\
\hline $\mathrm{T} 1$ & & 17 \\
\hline $\mathrm{T} 2$ & & 34 \\
\hline $\mathrm{T} 3$ & & 81 \\
\hline $\mathrm{T} 4$ & & 20 \\
\hline \multicolumn{3}{|l|}{$\mathrm{N}$ category } \\
\hline No & & 110 \\
\hline N1 & & 26 \\
\hline $\mathrm{N} 2$ & & 18 \\
\hline \multicolumn{3}{|l|}{ M category } \\
\hline M0 & & 142 \\
\hline M1 & & 12 \\
\hline \multicolumn{3}{|l|}{ Tumor size (mm) } \\
\hline Median \pm SD & $40 \pm 19$ & \\
\hline Preoperative chemotherapy & & 25 \\
\hline Anastomotic leakage & & 19 \\
\hline
\end{tabular}

Preoperative chemoradiotherapy was not performed in this series because of construction of a protective diverting stoma.

Anastomotic leakage

Among 154 patients, symptomatic AL occurred in 19 patients $(12.3 \%)$ : 15 were male and 4 were female. Their median BMI was 22.1 (range 17.0-27.3). The AL rate was $11.9 \%(12 / 101)$ in patients with upper rectal cancer and $13.2 \%(7 / 53)$ in patients with lower rectal cancer. AL requiring re-operation (grade $\mathrm{C}$ ) occurred in 8 cases (5.2\%: 8/154); diverting stoma in 6 cases, Hartmann 
Table 2 Clinical features of 19 patients with AL

\begin{tabular}{|c|c|c|}
\hline Characteristics & & No. of Patients \\
\hline \multicolumn{3}{|l|}{ Age (years) } \\
\hline Median (range) & $65(41-80)$ & \\
\hline \multicolumn{3}{|l|}{ BMI $\left(\mathrm{kg} / \mathrm{m}^{2}\right)$} \\
\hline Median (range) & $22.1(17.0-27.3)$ & \\
\hline \multicolumn{3}{|l|}{ Sex } \\
\hline Male & & 15 \\
\hline Female & & 4 \\
\hline \multicolumn{3}{|l|}{ Location } \\
\hline Upper & & 12 \\
\hline Lower & & 7 \\
\hline \multicolumn{3}{|l|}{ Detection time (day) } \\
\hline Median (range) & POD 6 (2-15) & \\
\hline \multicolumn{3}{|l|}{ Grade } \\
\hline $\mathrm{B}$ & & 12 \\
\hline $\mathrm{C}$ & & 7 \\
\hline \multicolumn{3}{|l|}{ Treatment } \\
\hline Diverting ileostomy & & 6 \\
\hline Hartmann procedure & & 1 \\
\hline Drainage & & 1 \\
\hline Transanal drainage & & 7 \\
\hline Antibiotics & & 4 \\
\hline \multicolumn{3}{|l|}{ Fistula } \\
\hline Rectovesical fistula & & 3 \\
\hline Rectovaginal fistula & & 1 \\
\hline \multicolumn{3}{|l|}{ Length of hospital stay } \\
\hline Median (range) & POD 45 (16-85) & \\
\hline Mortality & & 0 \\
\hline
\end{tabular}

procedure in one case, and drainage in one case. AL not requiring re-operation (grade B) occurred in 11 cases (7.1\%: 11/154); treated by transanal drainage [25] in seven cases, and by antibiotics in four cases. The median time at which AL was confirmed was postoperative day (POD) 6 (range 2-15). Fistula formation with vesicle and vagina occurred in three cases and one case, respectively. The median time to hospital discharge was POD 45 (range 16-85), and there was no death related to AL (Table 2).

Risk factors related to DST anastomotic leakage

On univariate analysis, symptomatic AL was significantly associated with tumor size $(\geq 5.0 \mathrm{~cm})$, operative time $(\geq 5.0 \mathrm{~h})$, operative bleeding $(\geq 100 \mathrm{ml})$, lateral lymph node dissection, multiple firings of the linear stapler $(\geq 3$ firings), and precompression before stapler firings (Tables 3, 4). In addition, there was a tendency for placement of a transanal tube to reduce $\mathrm{AL}$, with $P$ value less than 0.10 . No significant differences were found in terms of
Table 3 Univariate analysis of patient/tumor-related factors

\begin{tabular}{|c|c|c|c|}
\hline \multirow[t]{2}{*}{ Variables } & \multicolumn{2}{|c|}{ Patients with AL } & \multirow[b]{2}{*}{$P$ value } \\
\hline & $n$ & $\%$ & \\
\hline Age (years) & & & 0.43 \\
\hline$<70$ & $15 / 107$ & 14.0 & \\
\hline$\geq 70$ & $4 / 47$ & 8.5 & \\
\hline Sex & & & 0.59 \\
\hline Male & $15 / 111$ & 13.5 & \\
\hline Female & $4 / 43$ & 9.3 & \\
\hline BMI $\left(\mathrm{kg} / \mathrm{m}^{2}\right)$ & & & 0.75 \\
\hline$<25$ & $15 / 127$ & 11.8 & \\
\hline$\geq 25$ & $4 / 27$ & 14.8 & \\
\hline Albumin (g/dl) & & & 0.59 \\
\hline$<3.5$ & $0 / 8$ & 0.0 & \\
\hline$\geq 3.5$ & $19 / 146$ & 13.0 & \\
\hline Hemoglobin (g/dl) & & & 1 \\
\hline$<11$ & $2 / 15$ & 13.3 & \\
\hline$\geq 11$ & $17 / 139$ & 12.2 & \\
\hline Location & & & 0.80 \\
\hline Upper & $12 / 101$ & 11.9 & \\
\hline Lower & $7 / 53$ & 13.2 & \\
\hline Tumor size $(\mathrm{cm})$ & & & 0.001 \\
\hline$<5.0$ & $7 / 111$ & 6.3 & \\
\hline$\geq 5.0$ & $12 / 43$ & 27.9 & \\
\hline $\mathrm{T}$ category & & & 1 \\
\hline Tis, T1, T2 & $6 / 53$ & 11.3 & \\
\hline T3, T4 & $13 / 101$ & 12.8 & \\
\hline $\mathrm{N}$ category & & & 1 \\
\hline N0 & $14 / 110$ & 12.7 & \\
\hline $\mathrm{N} 1, \mathrm{~N} 2$ & $5 / 44$ & 11.4 & \\
\hline UICC-TNM Stage & & & 1 \\
\hline I, II & $13 / 103$ & 12.6 & \\
\hline III, IV & $6 / 51$ & 11.8 & \\
\hline Lymphatic invasion & & & 1 \\
\hline Negative & $13 / 103$ & 12.6 & \\
\hline Positive & $6 / 51$ & 11.8 & \\
\hline Venous invasion & & & 1 \\
\hline Negative & $8 / 67$ & 11.9 & \\
\hline Positive & $11 / 87$ & 12.6 & \\
\hline Preoperative chemotherapy & & & 0.52 \\
\hline No & $15 / 129$ & 11.6 & \\
\hline Yes & $4 / 25$ & 16.0 & \\
\hline
\end{tabular}

age, sex, BMI, preoperative serum albumin and hemoglobin levels, preoperative chemotherapy, tumor location, UICC-TNM stage, lymphatic invasion, venous invasion, level of IMA ligation, simultaneous resection of other organs, height of the anastomosis, removal of crossing point where two staple lines intersected, size of the circular stapler, and placement of a pelvic drain. In the 
Table 4 Univariate analysis of surgery-related factors

\begin{tabular}{|c|c|c|c|}
\hline \multirow[t]{2}{*}{ Variables } & \multicolumn{2}{|c|}{ Patients with AL } & \multirow[b]{2}{*}{$P$ value } \\
\hline & $n$ & $\%$ & \\
\hline Operative time (min) & & & 0.049 \\
\hline$<300$ & $7 / 90$ & 7.8 & \\
\hline$\geq 300$ & $12 / 64$ & 18.7 & \\
\hline Intraoperative bleeding (ml) & & & 0.037 \\
\hline$<100$ & $11 / 120$ & 9.2 & \\
\hline$\geq 100$ & $8 / 34$ & 23.5 & \\
\hline Ligation of IMA & & & 0.29 \\
\hline High ligation & $15 / 133$ & 11.3 & \\
\hline Low ligation & $4 / 21$ & 19.0 & \\
\hline Lateral lymph node dissection & & & 0.009 \\
\hline No & $15 / 146$ & 10.3 & \\
\hline Yes & $4 / 8$ & 50.0 & \\
\hline Simultaneous resection & & & 0.60 \\
\hline No & $19 / 147$ & 12.9 & \\
\hline Yes & $0 / 7$ & 0.0 & \\
\hline $\begin{array}{l}\text { Anastomosis level from anal } \\
\text { verge }(\mathrm{mm})\end{array}$ & & & 0.27 \\
\hline$<30$ & $4 / 25$ & 16.0 & \\
\hline$\geq 30$ & $9 / 107$ & 8.4 & \\
\hline $\begin{array}{l}\text { Number of cartridges for } \\
\text { rectal transection }\end{array}$ & & & 0.041 \\
\hline 1.2 & $13 / 131$ & 9.9 & \\
\hline$\geq 3$ & $6 / 23$ & 26.0 & \\
\hline Crossing point of staple lines & & & 0.29 \\
\hline Absent & $11 / 106$ & 10.4 & \\
\hline Present & $8 / 46$ & 17.4 & \\
\hline Precompression before stapler firings & & & 0.008 \\
\hline No & $8 / 28$ & 28.6 & \\
\hline Yes & $11 / 126$ & 8.7 & \\
\hline Diameter of circular stapler (mm) & & & 1 \\
\hline 25 & $1 / 16$ & 6.3 & \\
\hline 29 & $13 / 121$ & 10.7 & \\
\hline Placement of a pelvic drain & & & 0.18 \\
\hline No & $5 / 24$ & 20.8 & \\
\hline Yes & $14 / 130$ & 10.8 & \\
\hline Placement of a transanal tube & & & 0.096 \\
\hline No & $6 / 26$ & 23.1 & \\
\hline Yes & $13 / 128$ & 10.2 & \\
\hline
\end{tabular}

precompression group, we secured more than 30-s intervals before each firing of the linear stapler, and more than 2-min interval before firing of the circular stapler, while we did not secure such enough precompression time in the nonprecompression group. We previously reported that precompression before stapler firings is a critical factor for successful staple formation in an animal model [19].
Table 5 Multivariate analysis of risk factors associated with AR

\begin{tabular}{llll}
\hline Variables & OR & $95 \%$ CI & $P$ value \\
\hline Tumor size $(\geq 5 \mathrm{~cm})$ & 4.01 & $1.25-12.89$ & 0.020 \\
Operative time $(\geq 300 \mathrm{~min})$ & 2.9 & $0.77-11.14$ & 0.114 \\
Intraoperative bleeding $(\geq 100 \mathrm{ml})$ & 0.88 & $0.23-3.31$ & 0.849 \\
Lateral lymph node dissection (yes) & 3.67 & $0.63-21.34$ & 0.148 \\
$\begin{array}{l}\text { Number of cartridges for rectal } \\
\text { transection }(\geq 3)\end{array}$ & 0.90 & $0.22-3.71$ & 0.887 \\
$\begin{array}{l}\text { Precompression before stapler firings } \\
\quad \text { (no) }\end{array}$ & 4.58 & $1.22-17.20$ & 0.024 \\
\hline OR odds ratio, $C I$ confidence interval & & & \\
\hline
\end{tabular}

Therefore, we analyzed the effect of precompression before stapler firings in this clinical setting, and found that it significantly reduced the AL rate $28.6 \%$ in the non-precompression group vs. $8.7 \%$ in the precompression group; $P=0.008)$.

In the multivariate analysis including factors with a $P$ value of $\leq 0.05$, only tumor size $(\geq 5.0 \mathrm{~cm})$ and precompression before stapler firings remained significantly correlated with AL (Table 5; odds ratio [OR] 4.01; $95 \%$ confidence interval $[\mathrm{CI}] 1.25-12.89 ; P=0.02$ and $\mathrm{OR}$ 4.58; CI 1.22-17.20; $P=0.024$, respectively).

Based on the timing to be confirmed AL, 19 patients with developing $\mathrm{AL}$ were classified into two groups; the early leakage group (POD 5 or less; $n=8$ ) and the late leakage group (POD more than $5 ; n=11$ ) (Table 6). Regarding the severity of AL, grade C occurred in $50 \%$ (4/ 8 ) of the early leakage group, whereas in $36.3 \%(4 / 11)$ of the late leakage group. Emergency operation was needed due to major leakage in $37.5 \%(3 / 8)$ of the early leakage group, whereas in $18.2 \%(2 / 11)$ of the late leakage group. Importantly, precompression before stapler firings tended to reduce the early leakage compared with the late leakage (25\% (2/8) and $81.8 \%(9 / 11)$, respectively). In addition, multiple firings of the linear stapler ( $\geq 3$ firings) also tended to be associated with the early leakage compared with the late leakage $(62.5 \%(5 / 8)$ and $9.1 \%(1 / 11)$, respectively).

\section{Discussion}

$\mathrm{AL}$ is a major problem in patients who undergo operations for rectal cancers. It is associated with not only postoperative morbidity and mortality, but also local recurrence and patient's survival [8-10]. Several risk factors, including age, sex, intraoperative bleeding, obesity, preoperative chemoradiotherapy, protective diverting stoma, pelvic drainage, tumor size, tumor location, and the level of anastomosis, have been reported to be associated with $\mathrm{AL}$ after open LAR [11, 26-29]. In contrast, only a few studies 
Table 6 Type of AL

\begin{tabular}{|c|c|c|}
\hline Variables & $\begin{array}{l}\text { Early leakage } \\
(n=8)\end{array}$ & $\begin{array}{l}\text { Late leakage } \\
(n=11)\end{array}$ \\
\hline \multicolumn{3}{|l|}{ Detection time } \\
\hline Median \pm SD, POD days & $3.5 \pm 1.4$ & $10 \pm 3.6$ \\
\hline \multicolumn{3}{|l|}{ Grade } \\
\hline B & 4 & 7 \\
\hline $\mathrm{C}$ & 4 & 4 \\
\hline \multicolumn{3}{|l|}{ Emergency operation } \\
\hline No & 5 & 9 \\
\hline Yes & 3 & 2 \\
\hline \multicolumn{3}{|l|}{ Tumor size } \\
\hline Median $\pm \mathrm{SD}(\mathrm{mm})$ & $63 \pm 17$ & $48 \pm 17$ \\
\hline \multicolumn{3}{|c|}{ Anastomosis level from anal verge } \\
\hline Median $\pm \mathrm{SD}(\mathrm{mm})$ & $28 \pm 16$ & $42 \pm 23$ \\
\hline \multicolumn{3}{|l|}{ Operative time (min) } \\
\hline$<300$ & 4 & 3 \\
\hline$\geq 300$ & 4 & 8 \\
\hline \multicolumn{3}{|l|}{ Intraoperative bleeding $(\mathrm{ml})$} \\
\hline$<100$ & 4 & 7 \\
\hline$\geq 100$ & 4 & 4 \\
\hline \multicolumn{3}{|l|}{ Lateral lymph node dissection } \\
\hline No & 6 & 9 \\
\hline Yes & 2 & 2 \\
\hline \multicolumn{3}{|c|}{ Number of cartridges for rectal transection } \\
\hline 1.2 & 3 & 10 \\
\hline$\geq 3$ & 5 & 1 \\
\hline \multicolumn{3}{|c|}{ Precompression before stapler firings } \\
\hline No & 6 & 9 \\
\hline Yes & 2 & 2 \\
\hline \multicolumn{3}{|l|}{ Placement of a transanal tube } \\
\hline No & 4 & 2 \\
\hline Yes & 4 & 9 \\
\hline
\end{tabular}

have examined risk factors for AL after laparoscopic LAR [14-18]. Several studies reported that laparoscopic surgery and open surgery for rectal cancer did not differ in terms of the $\mathrm{AL}$ rate $[2,3,5,30]$. Laparoscopic rectal surgery provides an excellent operative field in a narrow pelvic space, and enables the preservation of autonomic nervous system more precisely. However, rectal transection using a laparoscopic linear stapler is relatively difficult when compared with open surgery because of the width and limited performance of the linear stapler. The devices and techniques used for laparoscopic LAR are different from those used for open LAR, which suggests that the risk factors for AL after laparoscopic LAR may also differ from those after open LAR. In the present study, multivariate analysis identified tumor size $(\geq 5.0 \mathrm{~cm})$ and precompression before stapler firings as independent risk factors of symptomatic AL after laparoscopic LAR with DST anastomosis (Table 5; $P=0.02$ and 0.024 , respectively). Tumor size is well known to be a risk factor for AL after LAR [29]. Pelvic space is limited, and so tumor size could adversely affect the ease of rectal transection and anastomosis. We previously reported that a sufficient amount of precompression time before stapler firings resulted in reduced intestinal wall thickness and proper staple formation in an animal model [19], which was in agreement with the result of this clinical study. This study provided the first evidence that precompression before stapler firings was associated with $\mathrm{AL}$ in a clinical setting. We assume that precompression time and proper cartridge selection according to the wall thickness were critical to achieve secure staple formation.

Previous studies reported that the use of more than three cartridges for rectal transection was a risk factor for $\mathrm{AL}$ after laparoscopic LAR [14, 15, 17]. When the number of stapler cartridges increases, there is a concern that an increased number of stapler firings may lead to small defects between the staple lines and, in turn, cause AL. In the present study, AL occurred in $26.0 \%(6 / 23)$ of the cases in which more than three cartridges were used, whereas in only $9.9 \%(13 / 131)$ of the cases in which one or two cartridges were used (Table $4 ; P=0.041$ ). In addition, the AL rate in cases with two cartridges was $10.9 \%(11 / 101)$, whereas that in cases with one cartridge was $6.7 \%(2 / 30)$. Although there was no statistical significance in multivariate analysis (Table 5), we assume that the efforts to reduce the number of linear stapler seem to be recommended.

Several surgical techniques for laparoscopic LAR have been proposed to decrease AL. Ito et al. [15] reported that vertical rectal transection through an additional suprapubic site was useful for avoiding multiple stapler firings and decreasing the AL rate. Kuroyanagi et al. [23] reported that rectal transection was performed using two cartridges in most cases, with harmonious operator-assistant movement. They insisted the technical efforts to remove the crossing point of staple lines, which might otherwise be the cause of AL. In the present study, we analyzed whether the remnant crossing point could increase the AL rate, and found that it was not significantly associated with AL (Table 4); AL occurred in $17.4 \%(8 / 46)$ of cases with remnant crossing point, whereas in $10.4 \%(11 / 106)$ of cases without remnant crossing point $(P=0.29)$. We assume that surgeons do not have to persist to remove the crossing point, especially when the crossing point is placed near the edge of the rectal stump and so removal of the crossing point is technically difficult. To our knowledge, this is the first study to investigate the effect of the remnant crossing point in a clinical setting.

Some studies recently reported that a transanal tube was important to prevent AL after LAR [31, 32], although other 
study reported that a transanal stent did not reduce AL [33]. In theory, a transanal tube decreases the intraluminal pressure around the anastomotic site, and protects the anastomosis from watery stool and flatus when gastrointestinal motility improves. In the present study, AL occurred in $10.2 \%(13 / 128)$ of cases with a transanal tube, whereas in $23.1 \%(6 / 26)$ of cases without a transanal tube (Table 4; $P=0.096$ ). Although there was no statistical significance, we assume that a transanal tube seems to be useful to reduce the AL rate. We usually remove a transanal tube at 5-7 days after surgery.

A number of studies have reported that lower anastomosis level is an important risk factor for $\mathrm{AL}$ after LAR [27, 28]. However, the correlation between anastomosis level and AL was not statistically significant in the present study: AL rates for low anastomosis (height of the anastomosis from the anal verge was less than $3 \mathrm{~cm}$ ) and high anastomosis (height of the anastomosis from the anal verge was $3 \mathrm{~cm}$ or more) were $16.0 \%(4 / 25)$ and $8.4 \%$ (9/107), respectively (Table $4 ; P=0.27$ ). In addition, the correlation between tumor location and $\mathrm{AL}$ was not significant (Table 3; $P=0.80$ ). Although there was no statistical significance, the height of the anastomosis or the tumor location can reflect technical difficulties of laparoscopic LAR. All surgeries in the present study were conducted by well-experienced, board-certified laparoscopic colorectal surgeons. This minimized the risk of bias potentially associated with the early phase of the learning curve of surgeons, and with any inter-institutional variability in a multi-institutional trial.

There is still debate as to whether the creation of diverting stoma reduces AL. A recent randomized controlled study showed that the creation of diverting stoma reduced the incidence and clinical significance of AL [34]. A considerable amount of retrospective studies have also described the beneficial effect of a diverting stoma on $\mathrm{AL}$ $[11,35,36]$. On the other hand, there are some studies that the creation of a diverting stoma did not reduce the AL rate $[37,38]$. However, it is generally agreed that the creation of a diverting stoma can reduce the incidence of the severe complications that $\mathrm{AL}$ can cause. In the present study, cases with a diverting stoma were excluded from the analysis, because the creation of a diverting stoma seems to effectively reduce the clinical significance of AL and could be considered in high-risk patients.

In conclusion, we demonstrated that tumor size and precompression before stapler firings were independent risk factors for $\mathrm{AL}$ after laparoscopic LAR with DST anastomosis. In addition, precompression before stapler firings and multiple firings of the linear stapler tended to be associated with the AL occurring in early postoperative period. This study provides interesting data in the effort to reduce AL. However, because of the retrospective nature, the limited number of patients, and the likely multifactorial nature of $\mathrm{AL}$, it is hard to draw robust conclusions. The outcomes of this study could not be corrected in a case-mix adjusted comparison, since this requires a large amount of cases to prevent over-fitting. Further studies including a large multi-institutional randomized controlled study are required to identify risk factors of $\mathrm{AL}$ and to develop the approaches to reduce this risk for patients with rectal cancers who undergo laparoscopic LAR.

Acknowledgments The authors thank medical staffs and residents of Kyoto University Hospital gastrointestinal surgery for their participation in this study. We could not have completed the study without their diligence and support.

Disclosures Drs. Kenji Kawada, Suguru Hasegawa, Koya Hida, Kenjiro Hirai, Kae Okoshi, Akinari Nomura, Junichiro Kawamura, Satoshi Nagayama and Yoshiharu Sakai have no conflicts of interest or financial ties to disclose.

Open Access This article is distributed under the terms of the Creative Commons Attribution License which permits any use, distribution, and reproduction in any medium, provided the original author(s) and the source are credited.

\section{References}

1. Heald RJ, Husband EM, Ryall RD (1982) The mesorectum in rectal cancer surgery-the clue to pelvic recurrence? Br J Surgery 69:613-616

2. Guillou PJ, Quirke P, Thorpe H, Walker J, Jayne DG, Smith AM, Heath RM, Brown JM, MRC CLASICC trial group (2005) Shortterm endpoints of conventional versus laparoscopic-assisted surgery in patients with colorectal cancer (MRC CLASICC trial): multicentre, randomised controlled trial. Lancet 365:1718-1726

3. Zhou ZG, Hu M, Li Y, Lei WZ, Yu YY, Cheng Z, Li L, Shu Y, Wang TC (2004) Laparoscopic versus open total mesorectal excision with anal sphincter preservation for low rectal cancer. Surg Endosc 18:1211-1215

4. Lelong B, Bege T, Esterni B, Guiramand J, Turrini O, Moutardier V, Magnin V, Monges G, Pernoud N, Blache JL, Giovannini M, Delpero JR (2007) Short-term outcome after laparoscopic or open restorative mesorectal excision for rectal cancer: a comparative cohort study. Dis Colon Rectum 50:176-183

5. Lujan J, Valero G, Hernandez Q, Sanchez A, Frutos MD, Parrilla P (2009) Randomized clinical trial comparing laparoscopic and open surgery in patients with rectal cancer. Br J Surg 96:982-989

6. Milsom JW, de Oliveira O, Jr Trencheva KI, Pandey S, Lee SW, Sonoda T (2009) Long-term outcomes of patients undergoing curative laparoscopic surgery for mid and low rectal cancer. Dis Colon Rectum 52:1215-1222

7. Kang CY, Halabi WJ, Chaudhry OO, Nguyen V, Pigazzi A, Carmichael JC, Mills S, Stamos MJ (2013) Risk factors for anastomotic leakage after anterior resection for rectal cancer. JAMA Surg 148:65-71

8. Branagan G, Finnis D, Wessex Colorectal Cancer Audit Working Group (2005) Prognosis after anastomotic leakage in colorectal surgery. Dis Colon Rectum 48:1021-1026

9. den Dulk M, Marijnen CA, Collette L, Putter H, Påhlman L, Folkesson J, Bosset JF, Rödel C, Bujko K, van de Velde CJ (2009) Multicentre analysis of oncological and survival outcomes 
following anastomotic leakage after rectal cancer surgery. Br J Surg 96:1066-1075

10. Mirnezami A, Mirnezami R, Chandrakumaran K, Sasapu K, Sagar P, Finan P (2011) Increased local recurrence and reduced survival from colorectal cancer following anastomotic leak: systematic review and meta-analysis. Ann Surg 253:890-899

11. Peeters KC, Tollenaar RA, Marijnen CA, Klein Kranenbarg E, Steup WH, Wiggers T, Rutten HJ, van de Velde CJ, Dutch Colorectal Cancer Group (2005) Risk factors for anastomotic failure after total mesorectal excision of rectal cancer. Br J Surg 92:211-216

12. Paun BC, Cassie S, MacLean AR, Dixon E, Buie WD (2010) Postoperative complications following surgery for rectal cancer. Ann Surg 251:807-818

13. Snijders HS, Wouters MW, van Leersum NJ, Kolfschoten NE, Henneman D, de Vries AC, Tollenaar RA, Bonsing BA (2012) Meta-analysis of the risk for anastomotic leakage, the postoperative mortality caused by leakage in relation to the overall postoperative mortality. Eur J Surg Oncol 38:1013-1019

14. Park JS, Choi GS, Kim SH, Kim HR, Kim NK, Lee KY, Kang SB, Kim JY, Lee KY, Kim BC, Bae BN, Son GM, Lee SI, Kang $\mathrm{H}$ (2013) Multicenter analysis of risk factors for anastomotic leakage after laparoscopic rectal cancer excision: the Korean laparoscopic colorectal surgery study group. Ann Surg 257:665-671

15. Ito M, Sugito M, Kobayashi A, Nishizawa Y, Tsunoda $Y$, Saito N (2008) Relationship between multiple numbers of stapler firings during rectal division and anastomotic leakage after laparoscopic rectal resection. Int J Colorectal Dis 23:703-707

16. Yamamoto S, Fujita S, Akasu T, Inada R, Moriya Y, Yamamoto S (2012) Risk factors for anastomotic leakage after laparoscopic surgery for rectal cancer using a stapling technique. Surg Laparosc Endosc Percutan Tech 22:239-243

17. Kim JS, Cho SY, Min BS, Kim NK (2009) Risk factors for anastomotic leakage after laparoscopic intracorporeal colorectal anastomosis with a double stapling technique. J Am Coll Surg 209:694-701

18. Akiyoshi T, Ueno M, Fukunaga Y, Nagayama S, Fujimoto Y, Konishi T, Kuroyanagi H, Yamaguchi T (2011) Incidence of and risk factors for anastomotic leakage after laparoscopic anterior resection with intracorporeal rectal transection and double-stapling technique anastomosis for rectal cancer. Am J Surg 202:259-264

19. Nakayama S, Hasegawa S, Nagayama S, Kato S, Hida K, Tanaka E, Itami A, Kubo H, Sakai Y (2011) The importance of precompression time for secure stapling with a linear stapler. Surg Endosc 25:2382-2386

20. Japanese Society for Cancer of the Colon and Rectum (2009) Japanese classification of colorectal carcinoma, English 2nd ed. Kanehara, Tokyo

21. Sobin LH, Gospodarowicz MK, Wittekind Ch (eds) (2009) International union against cancer (UICC) TNM classification of malignant tumors, 7th edn. Wiley-Blackwell, West Sussex

22. Hasegawa S, Nagayama S, Nomura A, Kawamura J, Sakai Y (2008) Multimedia article. Autonomic nerve-preserving total mesorectal excision in the laparoscopic era. Dis Colon Rectum $51: 1279-1282$

23. Kuroyanagi H, Oya M, Ueno M, Fujimoto Y, Yamaguchi T, Muto T (2008) Standardized technique of laparoscopic intracorporeal rectal transection and anastomosis for low anterior resection. Surg Endosc 22:557-561
24. Rahbari NN, Weitz J, Hohenberger W, Heald RJ, Moran B, Ulrich A, Holm T, Wong WD, Tiret E, Moriya Y, Laurberg S, den Dulk M, van de Velde C, Büchler MW (2010) Definition and grading of anastomotic leakage following anterior resection of the rectum: a proposal by the International Study Group of Rectal Cancer. Surgery 147:339-351

25. Okoshi K, Masano Y, Hasegawa S, Hida K, Kawada K, Nomura A, Kawamura J, Nagayama S, Yoshimura T, Sakai Y (2013) Efficacy of transanal drainage for anastomotic leakage after laparoscopic low anterior resection of the rectum. Asian J Endosc Surg 6:90-95

26. Rullier E, Laurent C, Garrelon JL, Michel P, Saric J, Parneix M (1998) Risk factors for anastomotic leakage after resection of rectal cancer. Br J Surg 85:355-358

27. Yeh CY, Changchien CR, Wang JY, Chen JS, Chen HH, Chiang JM, Tang R (2005) Pelvic drainage and other risk factors for leakage after elective anterior resection in rectal cancer patients: a prospective study of 978 patients. Ann Surg 241:9-13

28. Jung SH, Yu CS, Choi PW, Kim DD, Park IJ, Kim HC, Kim JC (2008) Risk factors and oncologic impact of anastomotic leakage after rectal cancer surgery. Dis Colon Rectum 51:902-908

29. Eberl T, Jagoditsch M, Klingler A, Tschmelitsch J (2008) Risk factors for anastomotic leakage after resection for rectal cancer. Am J Surg 196:592-598

30. Aziz O, Constantinides V, Tekkis PP, Athanasiou T, Purkayastha S, Paraskeva P, Darzi AW, Heriot AG (2006) Laparoscopic versus open surgery for rectal cancer: a meta-analysis. Ann Surg Oncol 13:413-424

31. Xiao L, Zhang WB, Jiang PC, Bu XF, Yan Q, Li H, Zhang YJ, Yu F (2011) Can transanal tube placement after anterior resection for rectal carcinoma reduce anastomotic leakage rate? A singleinstitution prospective randomized study. World J Surg 35:1367-1377

32. Zhao WT, Hu FL, Li YY, Li HJ, Luo WM, Sun F (2013) Use of a transanal drainage tube for prevention of anastomotic leakage and bleeding after anterior resection for rectal cancer. World J Surg 37:227-232

33. Bülow S, Bulut O, Christensen IJ, Harling H, Rectal Stent Study Group (2006) Transanal stent in anterior resection does not prevent anastomotic leakage. Colorectal Dis 8:494-496

34. Matthiessen $P$, Hallböök $O$, Rutegård J, Simert G, Sjödahl R (2007) Defunctioning stoma reduces symptomatic anastomotic leakage after low anterior resection of the rectum for cancer: a randomized multicenter trial. Ann Surg 246:207-214

35. Eriksen MT, Wibe A, Norstein J, Haffner J, Wiig JN, Norwegian Rectal Cancer Group (2005) Anastomotic leakage following routine mesorectal excision for rectal cancer in a national cohort of patients. Colorectal Dis 7:51-57

36. Lefebure B, Tuech JJ, Bridoux V, Costaglioli B, Scotte M, Teniere P, Michot F (2008) Evaluation of selective defunctioning stoma after low anterior resection for rectal cancer. Int J Colorectal Dis 23:283-288

37. Enker WE, Merchant N, Cohen AM, Lanouette NM, Swallow C, Guillem J, Paty P, Minsky B, Weyrauch K, Quan SH (1999) Safety and efficacy of low anterior resection for rectal cancer: 681 consecutive cases from a specialty service. Ann Surg 230:544-552

38. Matthiessen $\mathrm{P}$, Hallböök $\mathrm{O}$, Andersson M, Rutegård J, Sjödahl R (2004) Risk factors for anastomotic leakage after anterior resection of the rectum. Colorectal Dis 6:462-469 